\title{
Review Article \\ Material Selection and Fabrication Processes for Flexible Conformal Antennas
}

\author{
Mahmuda Akter Monne $\mathbb{C}^{1},{ }^{1}$ Xing Lan, ${ }^{2}$ and Maggie Yihong Chen $\mathbb{D}^{1,3}$ \\ ${ }^{1}$ Material Science Engineering and Commercialization Program, Texas State University, San Marcos, TX 78666, USA \\ ${ }^{2}$ One Space Park, Northrop Grumman, Redondo Beach, CA 90278, USA \\ ${ }^{3}$ Ingram School of Engineering, Texas State University, San Marcos, TX 78666, USA
}

Correspondence should be addressed to Maggie Yihong Chen; maggie.chen@txstate.edu

Received 26 October 2017; Revised 28 December 2017; Accepted 13 February 2018; Published 20 May 2018

Academic Editor: Symeon Nikolaou

Copyright (c) 2018 Mahmuda Akter Monne et al. This is an open access article distributed under the Creative Commons Attribution License, which permits unrestricted use, distribution, and reproduction in any medium, provided the original work is properly cited.

Flexible antennas offer many advantages for communication, radar, RF identification, and energy harvesting applications. A review on the material selection and fabrication process of flexible antennas is presented since these aspects are critical to the antenna's overall electrical and mechanical performance. A number of different material and fabrication techniques are reviewed in detail for different types of antennas. In addition, experimental results are also discussed for these antennas, which further underlines the importance of material selection and the various fabrication processes.

\section{Introduction}

In recent years, a great deal of interest has arisen in both industry and academia for flexible electronics. In fact, this research area now occupies the top of the research pyramid of many national research agencies. The revenue of flexible electronics is estimated to be 3 billion USD in 2017 and projected to be over 300 billion USD in 2028 according to the latest market analysis report [1].

Moreover, flexible electronics is becoming an appealing candidate for the next generation of consumer electronics due to light weight, low cost of manufacturing, ease of fabrication, and the availability of inexpensive flexible substrates (i.e., papers, textiles, and plastics) [2]. Flexible electronic systems also incorporate flexible antennas to provide additional room for system trade-off space and design flexibility.

For example, a flexible antenna can be integrated onto a light weight, conformal, and flexible platform [3]. This kind of flexible antenna meets the requirement of different communication tasks using different antenna technologies (i.e., robotic devices or on human clothes, mandate a small size, light weight, and low power antenna system) [3]. On the other hand, because of the low profile of the flexible antenna design, coverage of the local network will be short $(\sim 10 \mathrm{~m})$ to medium range $(\sim 5 \mathrm{~km}-10 \mathrm{~km})[4,5]$.

A flexible substrate should be highly deformable and mechanically robust and must exhibit high tolerance levels of bending repeatability to comply with flexible technologies and integrated components [6]. Also, solvent resistivity, low cost (allowing large area, mass production), and moisture resistance can be additional requirements for substrate selection. There were various kinds of substrates utilized by researches, for example, steel [7], fabric [8], fluidic [9], paper [10], as well as synthesized materials. Among these, two most widely researched flexible substrate candidates are plastic and stainless steel [7]. Steel is not particularly deformable and heavier than plastic; therefore, it is unsuitable for many applications, particularly in wearable and display applications. Antennas were printed on $4 \mathrm{~mm}$ felt fabric textile [8], which is developed for wearable and conformal applications. However, it is hard to maintain the shape of fabric substrates during applications, as well as prone to environmental degradations. Paper substrate leads to potential electronic devices at low cost, which are also disposable and fully recyclable. A single-band antenna was printed and demonstrated on a $46 \mathrm{~mm} \times 30 \mathrm{~mm}$ paper substrate [10]. However, the high loss 


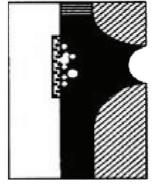

$\mathrm{t}>5 \mu \mathrm{s}$

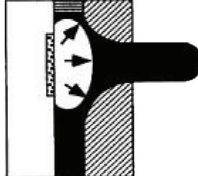

$\mathrm{t} \sim 10 \mu \mathrm{s}$

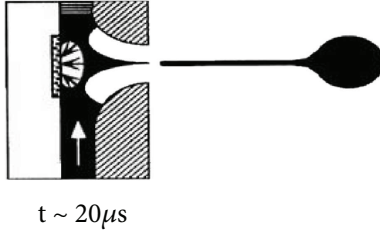

FIgURE 1: Drop formation by a thermal inkjet printer [36].

factor leads to reduced antenna efficiency due to either conduction losses, dielectric losses, or impedance mismatch [11]. On the other hand, plastic substrates are lighter and deformable alternatives with many suitable variants. With the DuPont brand Kapton polyimide film, the maximum fabrication temperature can be as high as $400^{\circ} \mathrm{C}$. Kapton also has low loss factor over a wide frequency range, high tensile strength, and dielectric strength [12].

There are four major types of flexible antennas, namely 3D-printed flexible antennas, passive and active wearable textile antennas, substrate-integrated waveguide antennas, and membrane-based antennas. Their fabrication process, performance, and application are discussed in detail in the following sections.

\section{3D-Printed Flexible Antennas}

This section reviews the currently available 3D printing technologies for the fabrication of flexible antennas. It also includes a method overview, advantages, and drawbacks of each technique, including inkjet printing, aerosol jet printing, and screen printing.

\subsection{D Inkjet Printing Technique}

2.1.1. Conductive and Insulating Materials. Conductive materials for printed and flexible antennas include various conductive inks and pastes which provide critical performance characteristics of a printed pattern. The choices of conductive material ink include the metallic solution of silver, gold, copper, and nickel nanoparticles, conductive polymers, carbon nanotubes, and graphene [13]. Also, each of these conductive materials offers different advantages to the final conductive system.

Conductive nanoparticle ink is based on conductive nanoparticles or nanoflakes dispensed in a liquid solvent usually in colloidal form [14-25]. A commercial silver ink (NovaCentrix, JSB-40G) in aqueous dispersion has $40 \%$ solid silver nanoflakes by weight with average particle size of $60-80 \mathrm{~nm}$. It also has a viscosity $(8-12 \mathrm{cP})$ which is suitable for inkjet print head. Viscosity of the ink can be increased by loading more nanoflakes, but it significantly increases the clogging rate. Curing the substrate after printing is an important step to evaporate the solvent so that only conductive material remains. Sintering could be in any form such as thermal curing, UV, or photonic curing. Sintering process like extended time of thermal curing or high-power UV or photonic curing can appreciably improve the conductivity of the printed patterns.

Another type of solution-based ink is silver metalorganic nanoparticle ink [26]. Jahn et al., Pabst et al., Calvert, and
Zhang et al. investigated silver printing from an aqueous transition metal complex- $\left[\mathrm{AgO}_{2} \mathrm{C}\left(\mathrm{CH}_{2} \mathrm{OCH}_{2}\right)_{3} \mathrm{H}\right]$ based metalorganic dispersion ink [27-30]. They achieved metallic silver-printed pattern conductivity as high as $2.7 \times 10^{7} \mathrm{~S} \mathrm{~m}^{-1}$. To achieve a layer-by-layer silver film growth using metalorganic dispersion ink, a sequential reactive inkjet (RI) process must be employed [27]. Reactive silver ink $\left(\mathrm{AgC}_{2} \mathrm{H}_{3} \mathrm{O}_{2}\right)$ (Sigma-Aldrich) is introduced to deploy the RI process. The RI process involves an initial printed metalorganic ink, followed by a secondary printed reactive ink. Interlayer adhesion can be improved by different surface treatments like oxygen plasma treatment.

Insulating materials are used for the dielectric layer during the fabrication of multilayer interconnects. There are few choices of dielectric material for printing technology that have excellent mechanical and thermal stability, chemical resistance, and electrical properties (e.g., high electrical breakdown field). Various forms of polymers can be suitable candidates for interlayer dielectrics and flexible devices. As an example, a form of polyimide, made from its precursor poly(amic acid) $18 \%$ of volume weight diluted with a little more than $80 \%$ of volume weight of 1-methyl-2-pyrrolidinone (NMP) upon heating and other chemical treatments, can be used as ink [31]. It is reported that polyketone resin dissolved in a solvent mixture of $50 \%$ ethyl lactate and $50 \% \alpha$-terpineol can be used as a suitable insulator, exhibiting a high electrical breakdown voltage of $17.5 \mathrm{MV} / \mathrm{m}$ [32]. Silicone elastomer is a two-part prepolymer liquid, which can be printed out as well [33]. In [33], it shows that the spin-on-glass can also be diluted to have the viscosity and solid content suitable for printing.

2.1.2. Operation of Inkjet Printer. Inkjet printers can be divided into two basic groups based on their operation procedure: continuous and drop-on-demand [34]. In continuous inkjet printers, the ink is first pumped through a nozzle forming a liquid jet. Secondly, the formed liquid jet is deflected by electrostatic plates to the paper or to a reservoir for recirculation.

Today, most inkjet printers are based on the drop formation process, which is called drop-on-demand (DOD) $[34,35]$. The drop-on-demand method provides smaller drops and higher placement accuracy compared to the continuous inkjet printers. In this method, the pulse that creates the ink drop can be generated either thermally or piezoelectrically. As seen in Figure 1, in a thermal inkjet printer, a heated plate causes a vapor bubble, which pushes the ink out through the nozzle. The total ejection time is a few microseconds, and the temperature of the plate can rise by about $300^{\circ} \mathrm{C}$ during the ejection.

Figure 2(a) shows the schematic of a shear-mode piezoelectric print head. In this type of print head, an electric field applied to a piezoceramic actuator element causes shear action deformation which is used to eject the ink through the nozzle [37]. The print head design shown in Figure 2(b) is called the bend-mode design. In this design, ink rejection is caused by the piezoceramic plates bonded to a diaphragm to form an array of bilaminar electromechanical transducers. 


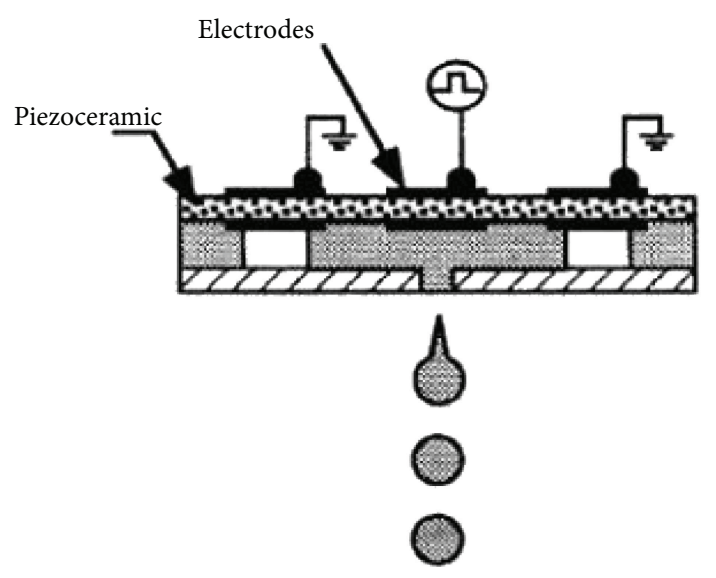

(a)

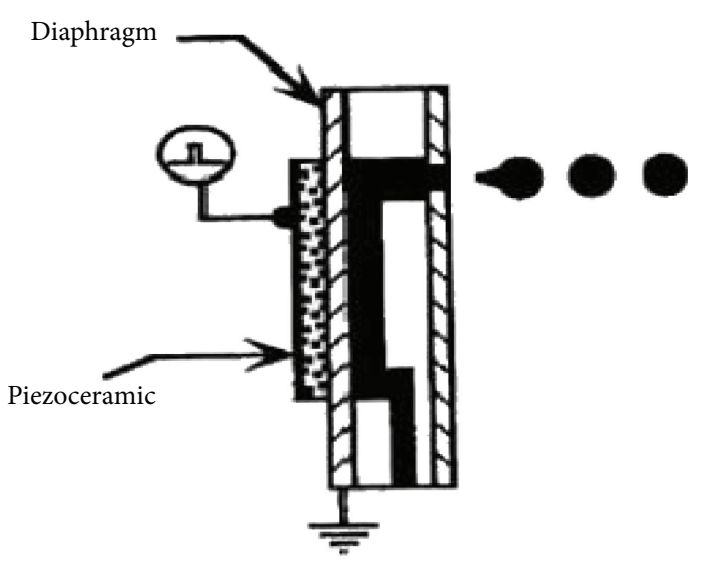

(b)

Figure 2: Design of a (a) shear-mode and (b) bend-mode piezoelectric inkjet print head [36].

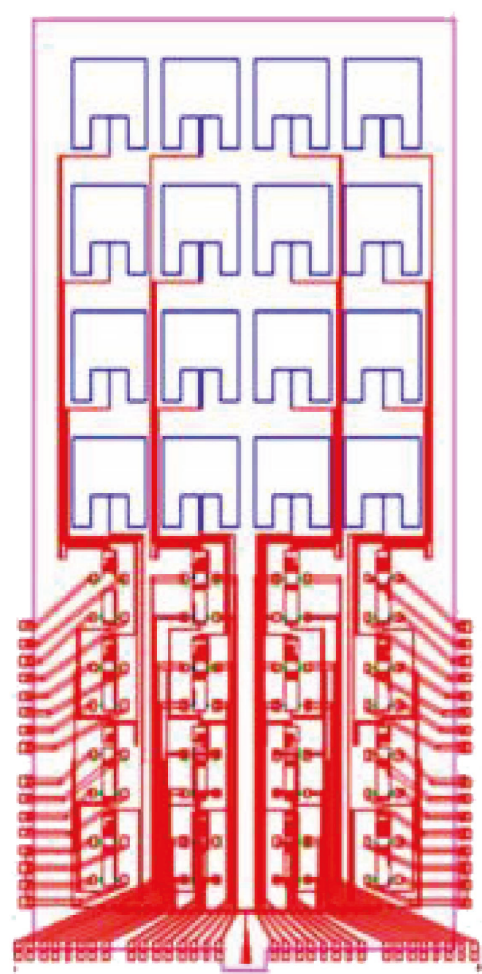

(a)

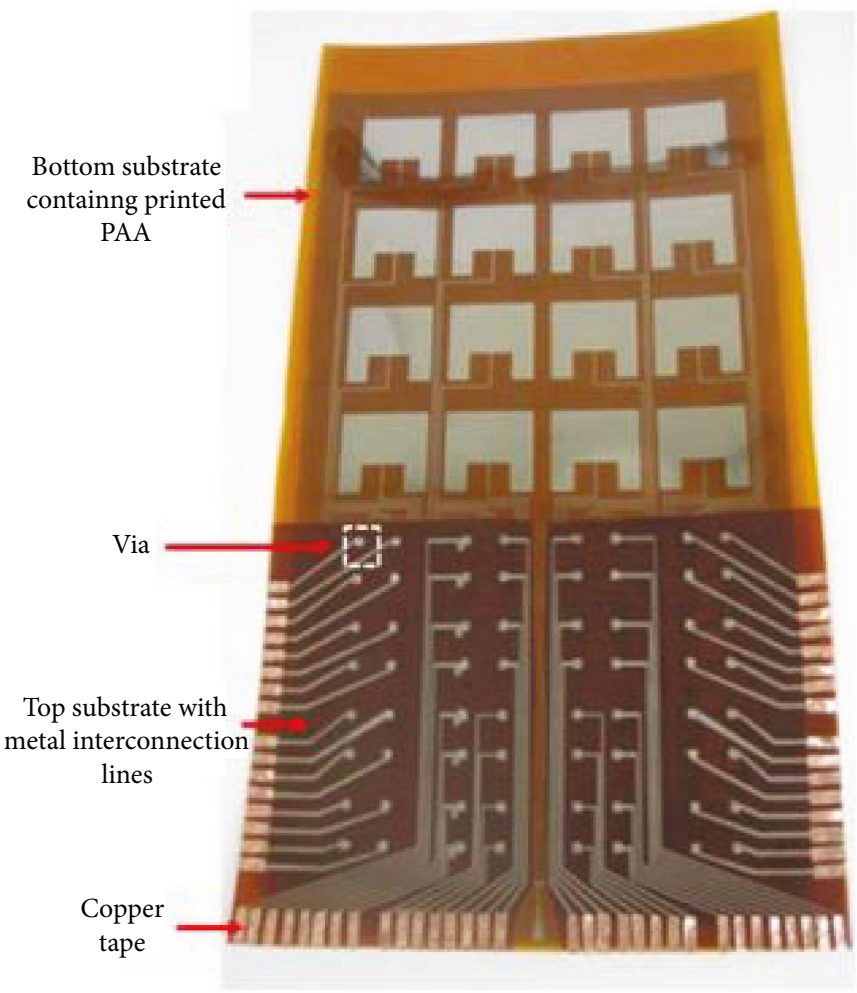

(b)

Figure 3: (a) Schematic layout of a 4 by 4 PAA subsystem with a multilayer interconnection scheme. (b) Photograph of the fully printed PAA system [39].

The print heads in a Tektronix's Phaser 300 and 350 and Epson's Color Stylus 400, 600, and 800 inkjet printers are of the bend-mode piezoceramic type [36]. The Fujifilm Dimatix Materials Printer is the most widely used inkjet printer for fabrication [38]. Since the printing is usually performed at room temperature $\left(25^{\circ} \mathrm{C}\right)$, this inkjet printer is capable of printing on a variety of substrates, including low temperature plastics. Additionally, during deposition, surface topology is also not an issue due to its contactless printing technique. This printing technique can also fill the contacts of multilayer interconnection without any obstacle. It is also possible to print multiple layers of different materials on top of each other.

2.1.3. Inkjet-Printed Antennas. Figure 3 shows the inkjetprinted $4 \times 4$ phased-array antenna (PAA) fabricated by Subbaraman et al. [39]. The entire PAA was inkjet printed using Fujifilm Dimatix Material Printer (DMP-2831), including the silver-based patch antenna elements and carbon nanotube (CNT) field-effect transistors (FETs) in the phaseshifting network. The DC control circuits for the CNT FETs were printed on a separate Kapton substrate, and multilayer 


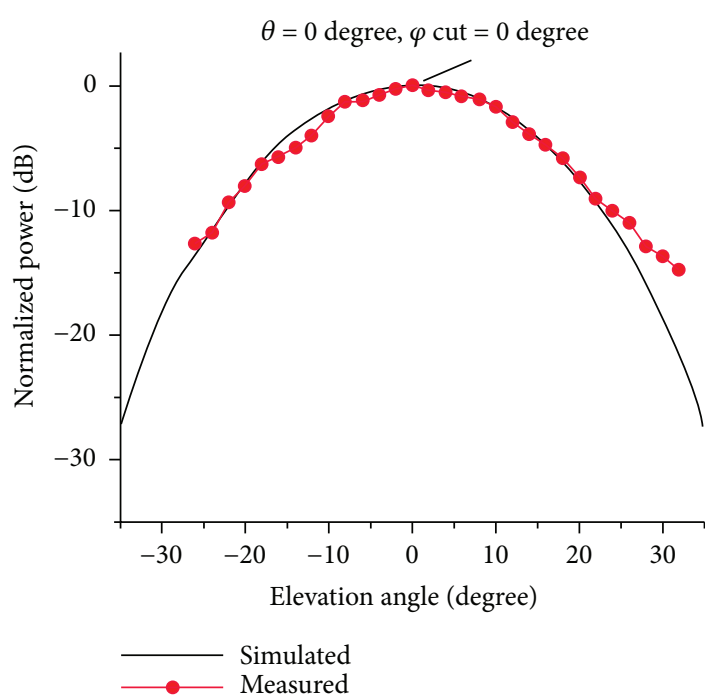

(a)

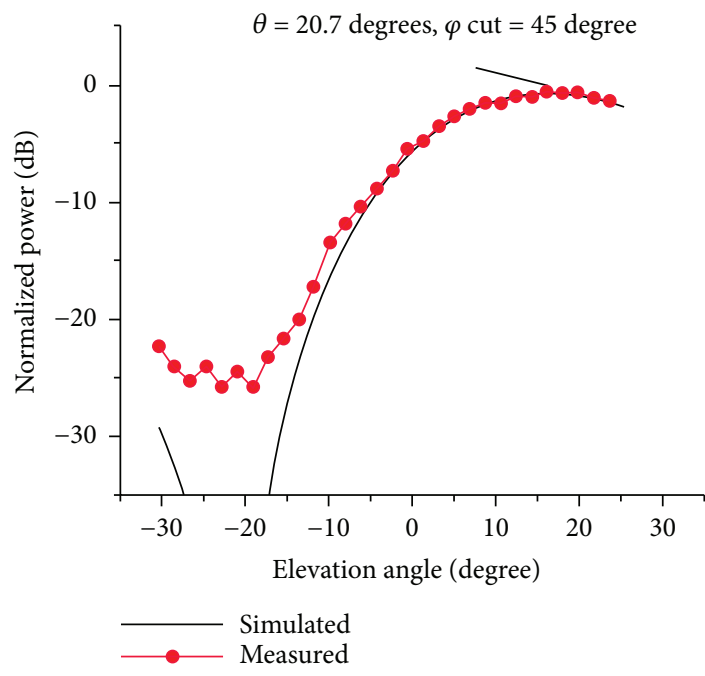

(c)

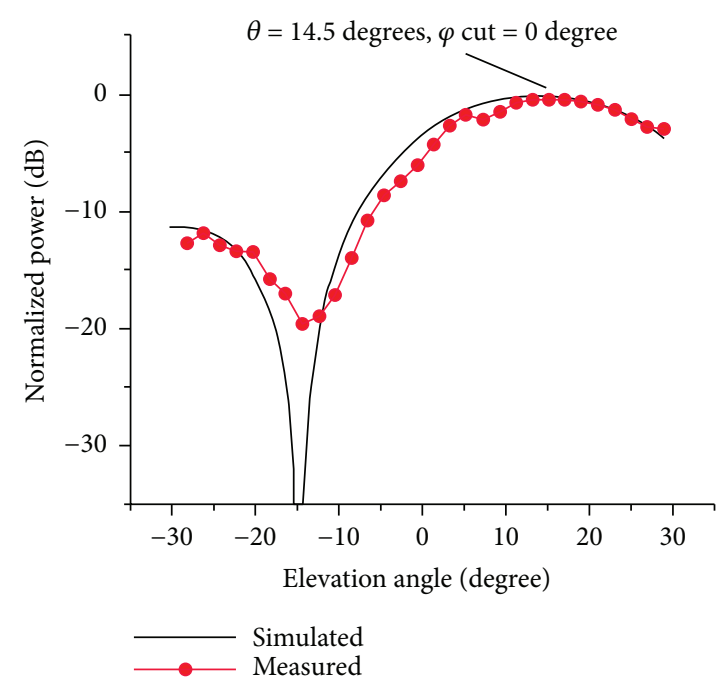

(b)

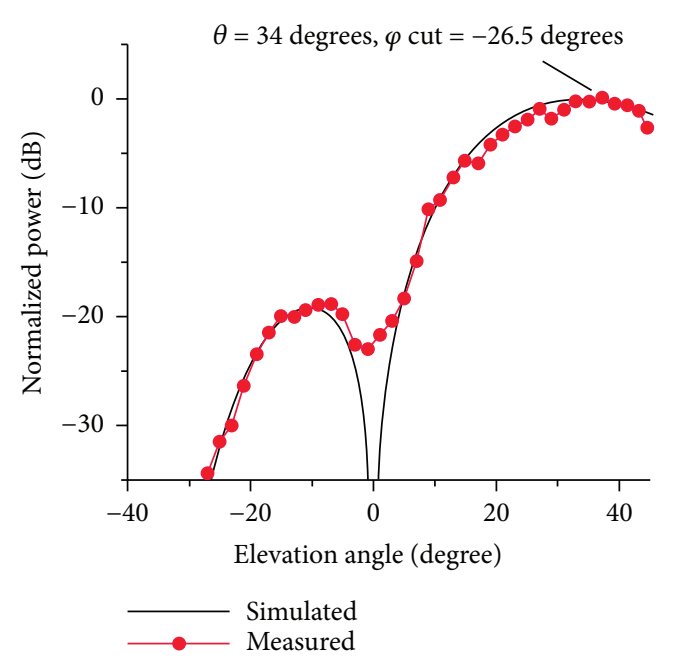

(d)

Figure 4: Measured and simulated far-field radiation patterns of the printed PAA system at $5 \mathrm{GHz}$ steering at (a) $\theta=0, \varphi=0$; (b) $\theta=14.5$, $\varphi=0$; (c) $\theta=20.7, \varphi=-45$; and (d) $\theta=34, \varphi=-26.5$ [39].

interconnects were realized through lamination and vias. The antenna was designed to work at $5 \mathrm{GHz}$ for Mars communication sponsored by NASA Glenn Research Center. Figure 4 compares the measured and simulated far-field radiation patterns at four different steering angles at $5 \mathrm{GHz}$ [39]. Without counting the loss of the transmission line, the gain of the fully printed PAA was as high as $14.6 \mathrm{dBi}$ with an efficiency of $58 \%$.

Compared to traditional antenna design, this lightweight, flexible, and conformal PAA is a promising candidate for on Mars communication, flexible portable wireless systems, as well as other airborne communication systems. Inkjet printing provides resolution down to 15 microns, which is important for high frequency applications. Furthermore, as shown in the above example, CNT FETs are printed together with the antenna patch to provide steering capability. The CNT FET is a four-layer (source/drain, channel, dielectric, and gate) $3 \mathrm{D}$ device with a channel size of 80 microns, which could not be realize with other flexible antenna technologies. Even though the viscosity of inkjet printable materials is limited to 8 to $12 \mathrm{cP}$, there are plenty of materials in the market that are within the range.

The following section describes another fabrication technique named aerosol jet printing technique. This printing technique not only provides resolution down to 5 microns but also be able to process materials with the viscosity from 1 to $1000 \mathrm{cP}$, which provides a wide choice of materials.

2.2. 3D Aerosol Jet Printing Technique. Aerosol jet printing, also known as maskless mesoscale material deposition or M3D [40], is another material deposition technique for printed electronics. Figure 5 shows the aerosol jet printing process. It begins with the atomization of ink by heating it up to $80^{\circ} \mathrm{C}$ [40]. Aerosol jet produces droplets of one to two micrometers in diameter. Finally, the atomized droplets are entrained in a gas stream and delivered to the print head. 


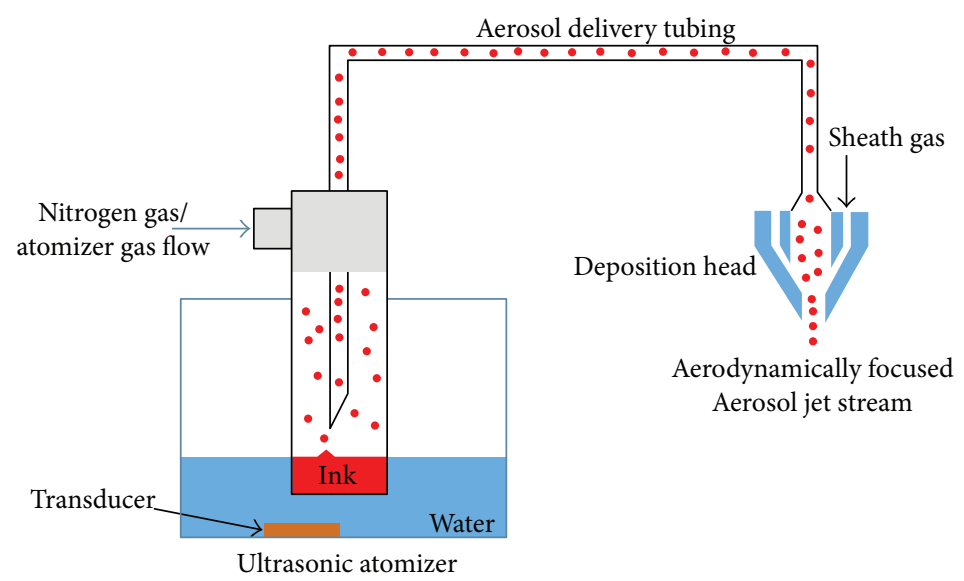

FIgURE 5: Aerosol jet printing operation process [41].

TABLE 1: Compatible materials for aerosol jet printing [43].

\begin{tabular}{lc}
\hline Conductive metals & Nanoparticle Ag, Au, Pt, Pd, ... \\
Conductive polymers & PEDOT, carbon nanotubes $(\mathrm{CNT})$ \\
Semiconductors & P3HT, PQT, CNTs, ... \\
Resistors & Carbon, metal oxide, ... \\
Dielectric & Epoxy, acrylic, PMMA, polyamide, \\
& PTFE, ... \\
\hline
\end{tabular}

An annular clean gas flow is also introduced around the aerosol stream, to pivot the droplets into a collimated beam of material. A converging nozzle is the exit path of the combined gas flow; it compresses the gas stream to a diameter as small as $10 \mu \mathrm{m}$ [41].

Predesigned electrical components are printed by moving the print head conjugated with a mechanically movable stop/ start shutter. The minimum printing resolution of an Optomec Aerosol Jet printer (AJ 300) is $5 \mu \mathrm{m}-10 \mu \mathrm{m}$ [40-42], with single-layer thicknesses from tens of nanometers to $>10 \mu \mathrm{m}$ [41]. For the application of millimeter size features and surface coating, a wide nozzle print head allows efficient printing. It should be noted that all the fabrication by this technique occurs without the use of any vacuum or pressure chambers at room temperature. Generally, very little splatter or overspray from the droplets occurs despite the high velocity of the printing process [42].

Literature review shows that a wide range of materials have been successfully deposited with the aerosol jet process which includes diluted thick film pastes, thermosetting polymers such as UV-curable epoxies, solvent-based polymers like polyurethane and polyimide, and biologic materials [43].

2.2.1. Material Compatibility. The aerosol jet can process a wide range of materials required for the manufacturing of printed electronic materials, such as conductors, semiconductors, resistors, and dielectrics/insulators [44]. Table 1 shows the combinations of materials printed layerwise to create differing functionality [43].

2.2.2. Aerosol Jet-Printed Antenna. Figure 6 shows the first printed near-field antenna by Optomec fabricated by an aerosol jet printer for near-field communication (NFC) [43]. According to the report from Optomec, it is found that the field strength of the printed antenna is $40 \%$ lower than other traditional antennas, but it meets ISO 14443 standard for operating at $13.56 \mathrm{MHz}$ in close proximity with a reader antenna [43]. Additionally, the performance was also improved later through additional power input or a lower resistance coil [43].

The intended application for this antenna was mainly for NFC, which was used in portable device such as a smartphone, to establish communication by bringing them within $4 \mathrm{~cm}$ (1.6 in) of each other. It also can be used in contactless payment systems, similar to those used in credit cards and electronic ticket smartcards, and allows mobile payment systems. Furthermore, this antenna can be used for social networking and sharing contacts, photos, videos, or files.

Aerosol jet printing provides resolution down to 5 microns, which is by far the most accurate fabrication technology. It is also widely adopted to print micron-size active components. It is also capable to process materials with the viscosity from 1 to $1000 \mathrm{cP}$, which provides a wide choice of materials.

The following section describes screen printing techniques for the fabrication of conformal antenna, which is one of the most cost-effective and simplest fabrication techniques used by manufacturers.

2.3. Antenna Fabrication by Screen Printing. Screen printing is based on a twisted screen with different thicknesses and thread densities. A rubber-edge blade is driven down forcing the screen into contact, producing a printed pattern with the glued substrate [45]. This process forces the ink to be ejected into the exposed areas of the screen as well on the substrate, and thus, the desired pattern is formed. The most common materials used in this technology are polyester and stainless steel. Figure 7 shows the screen printing process and fabricated flexible antenna, reported in [45].

Several RFIDs and flexible transparent antennas have been prototyped successfully using screen printing [46-48]. Figure 7 (b) shows a successful fabrication of a flexible 


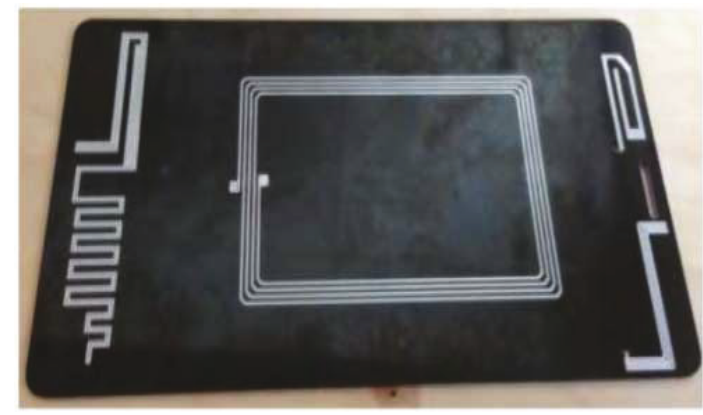

(a)

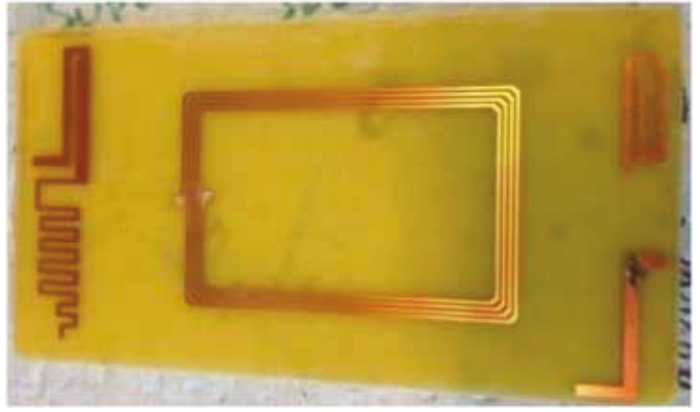

(b)

FIgure 6: Aerosol jet-printed near-field antenna by Optomec for near-field communication. (a) Printed with silver nanoparticle ink. (b) Printed with $\mathrm{Cu}$ nanoparticle ink [43].

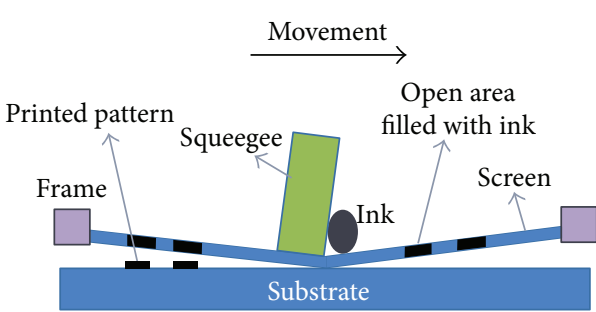

(a)

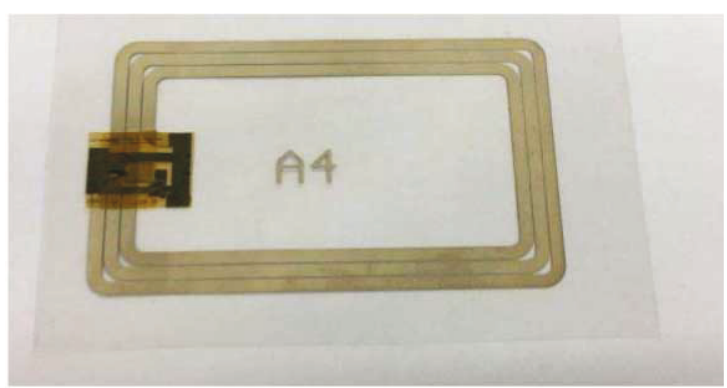

(b)

Figure 7: (a) Screen printing process [6]. (b) Screen-printed flexible antenna [45].

antenna for an interrogator application. The antenna demonstrated in this system was screen-printed by Quad Industries, utilizing printing inks developed by Agfa [45].

There are disadvantages associated with this technique, which includes the limited control over the thickness, number of passes, and resolution of the printed patterns. Layer consistency is also a challenge because of the change of ink viscosity and surface energy of the substrate due to the artifacts left by thermal curing of solvent-based inks [48].

In summary, 3D aerosol and inkjet printing are promising technologies that could be used to fabricate accurate antenna geometries with resolution down to 510 microns and active components such as switches and amplifiers. It could even be used to directly print on fabrics for wearable antennas.

\section{Wearable Textile Antennas}

Due to the recent miniaturization of wireless devices, the utilization of wearable textiles in antenna segment has been seen on the rise. A wearable antenna is a part of the clothing used for communication purposes, which also includes tracking and navigation, mobile computing, and public safety. It can also be used in telemedicine application.

3.1. Passive Wearable Antennas. One of the first proposals on wearable antennas appeared in 2001 [49]. The Salonen et al. proposed a GPS antenna with circular polarization where they have experimented five different synthetic fabric materials as dielectric substrates in 2004 [50]. Copper tape was used to make the conductive parts. The dielectric synthetic materials were from: Vellux ${ }^{\circledR}(5 \mathrm{~mm}$ thick fabric), synthetic felt (4 mm thick, nonwoven), Delinova $200^{\circledR}$ (made of polyamide Cordura ${ }^{\circledR}$ fibres laminated with Gore-Tex membrane and having a thickness of $0.5 \mathrm{~mm}$ ), fleece (a very soft polyester fabric with $4 \mathrm{~mm}$ thickness), and upholstery fabric [50,51]. The relative permittivity of the five fabrics was also measured, and the values ranged between 1.1 and 1.7 [50, 51]. Among all five studied fabrics, polyamide fibre (Cordura) was the most promising and interesting fabric for the development of a flexible antenna [51]. This material also has a property of constant thickness and high resistance, which allows this material to have more stable geometric dimensions for the antenna application.

Salonen et al. [52] presented a planar inverted-F antenna (PIFA), built on a flexible substrate for dual-band operation. Basically, it was intended to be placed on a shirt sleeve and operated at $900 \mathrm{MHz}$ and $2.4 \mathrm{GHz}$ [52]. The antenna showed good performance at upper band frequency $(2.4 \mathrm{GHz})$ even with a human body present, but lower band frequency $(900 \mathrm{MHz})$ radiation was not achieved [52].

Figure 8 shows the placement of wearable antenna on a human body [53] and fabricated textile patch antenna [54]. The material was a woven conductive fabric with a thickness of $0.125 \mathrm{~mm}$ and $0.05 \Omega /$ square surface resistance [53]. The material selection for a wearable antenna is a critical step to be robust and suitable for certain applications.

In [55], an aramid woven fabric which is flame resistant and suitable for integration into fire fighter garments 

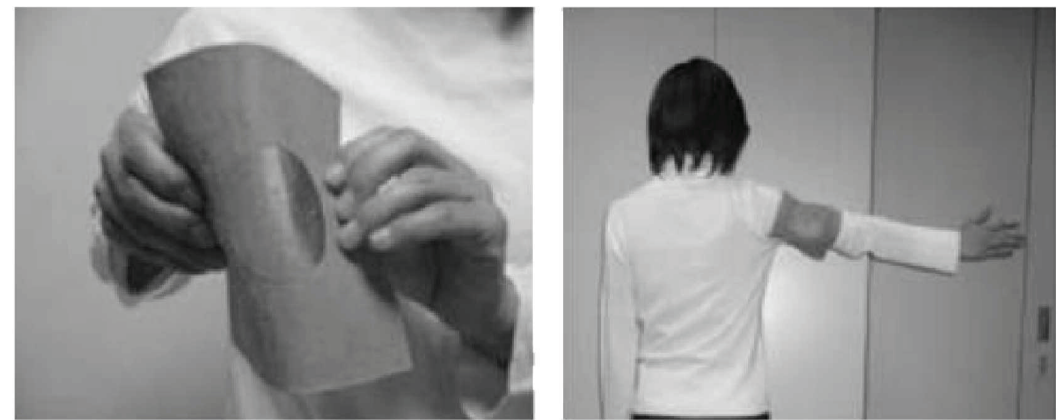

(a)

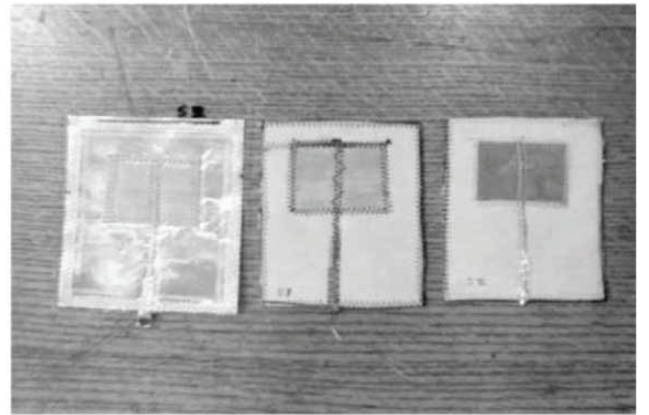

(b)

FIGURE 8: (a) Wearability of the antenna [53]. (b) Fabricated textile patch antennas. From left to right: applying copper tape, woven copper thread, and conductive spray [54].

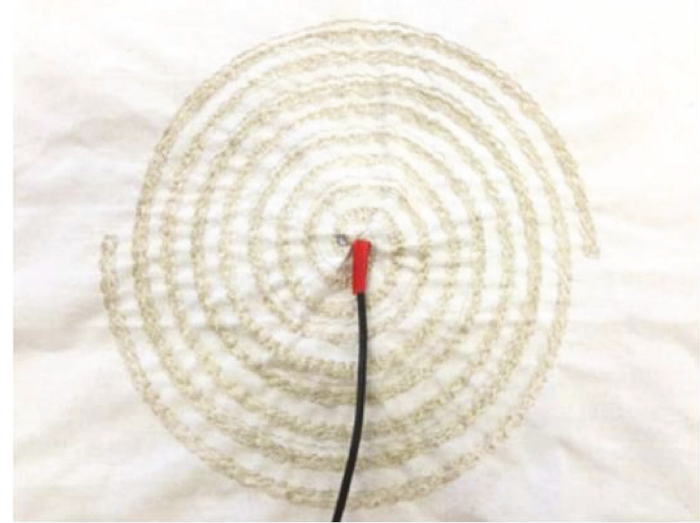

(a)

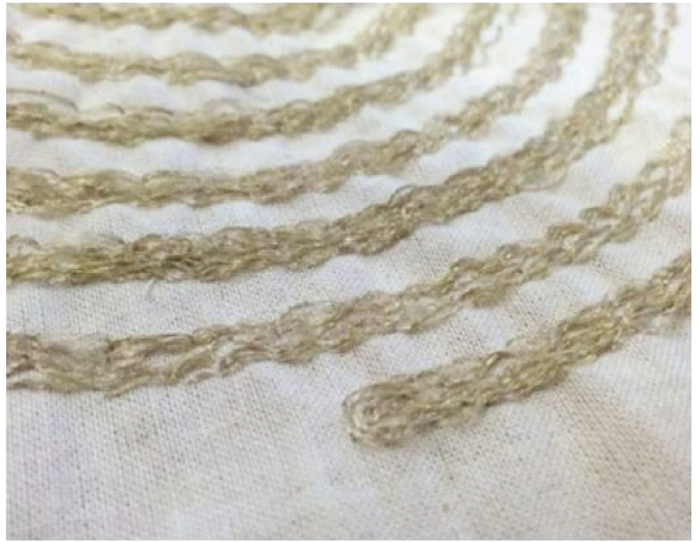

(b)

Figure 9: Embroidered spiral antenna. (a) Top view. (b) Zoomed-in view [60].

is reported. A highly conductive nylon fabric was used as the conductor. It has three metalized layers $(\mathrm{Ni} / \mathrm{Cu} / \mathrm{Ag})$ which provide high conductivity with the sheet resistance of $0.03 \Omega$ /square. Moreover, it also can provide flexibility and protection against corrosion.

Spiral antennas are one the most popular antennas because of their large bandwidth and low-profile properties. Various research papers have been published on the fabrication process of wearable spiral antennas [56-59]. The idea of embroidered spiral antennas is comparatively new. Investigations are still ongoing [57-59]. The density of the embroidered threads has been significantly elevated with the largest one reported in [58]. Figure 9 shows the embroidered spiral antenna. The antenna was fed by a $50 \Omega$ flexible coaxial cable.

Due to the large size and weight of the specific anthropomorphic mannequin (SAM) phantom, there is inherent difficulty in measuring the wearable spiral antenna with the conventional far-field measurement technique [60]. A novel cylindrical near-field measurement methodology was adopted to get the simulation results in Figures 10(a) and 10 (b). The distance reported was $2 \mathrm{~mm}$ between the antenna and a human body during testing. All the separations have $|\mathrm{S} 11|$ generally lower than $-5 \mathrm{~dB}$ for almost the entire frequency range above $0.5 \mathrm{GHz}$. The antenna is curved on the $y$-axis with $30^{\circ}, 40^{\circ}$, and $50^{\circ}$ curvature angles, respectively.

For the past few years, research has been going on to find out the effect of sewing types on the performance of different types of embroidered antennas. Three different sewing types have been studied in [61]. For a meandered sleeve monopole antenna, the sewing direction of spiral stitch was always along the direction of meandered line, so the antenna with spiral stitch has shown better performance. For a disc antenna, the sewing pattern of concentric circle stitch is similar to the current distribution of disc antenna. Therefore, it has demonstrated better performance. Based on this discussion, it can be concluded that the best RF performances can be obtained when the sewing direction is same as the current direction. Thus, different sewing types should be chosen for different antenna designs.

Additionally, [62] has presented the use of embroidered nonuniform mesh patch antennas which reported to maintain good antenna gain and efficiency for significantly reduced special conducting threads usage. It is found that the NMPAs have similar current and electric field distribution as a solid patch antenna at the $\mathrm{TM}_{01}$ mode. Furthermore, it is worth noting that the actual length of the embroidered 


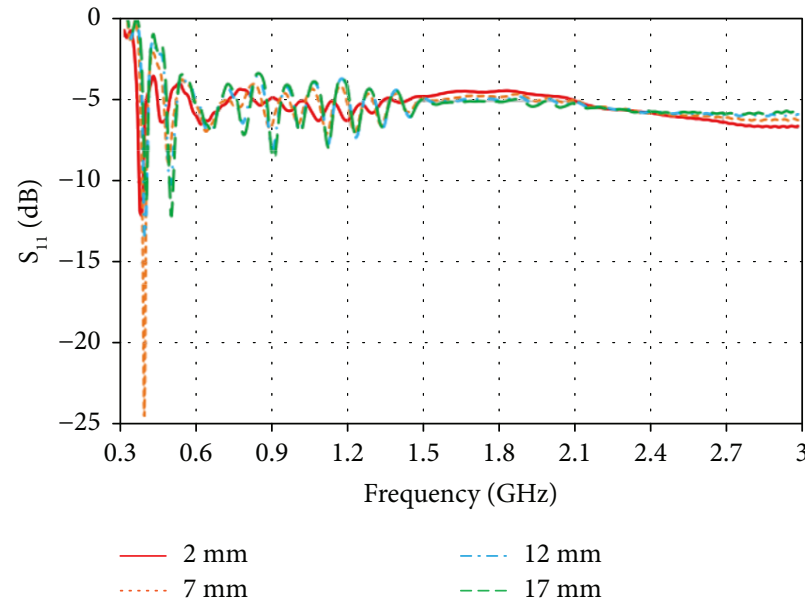

(a)

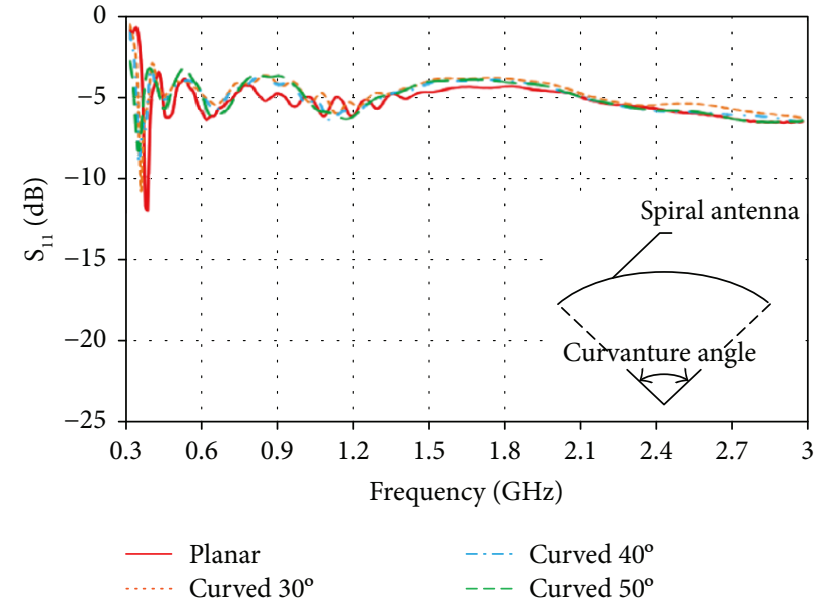

(b)

FIGURE 10: Simulated $|S 11|$ of the spiral antenna on the SAM phantom. (a) Planar spiral antenna at various distances from SAM phantom. (b) Different curvatures of the spiral antenna on the SAM phantom [60].

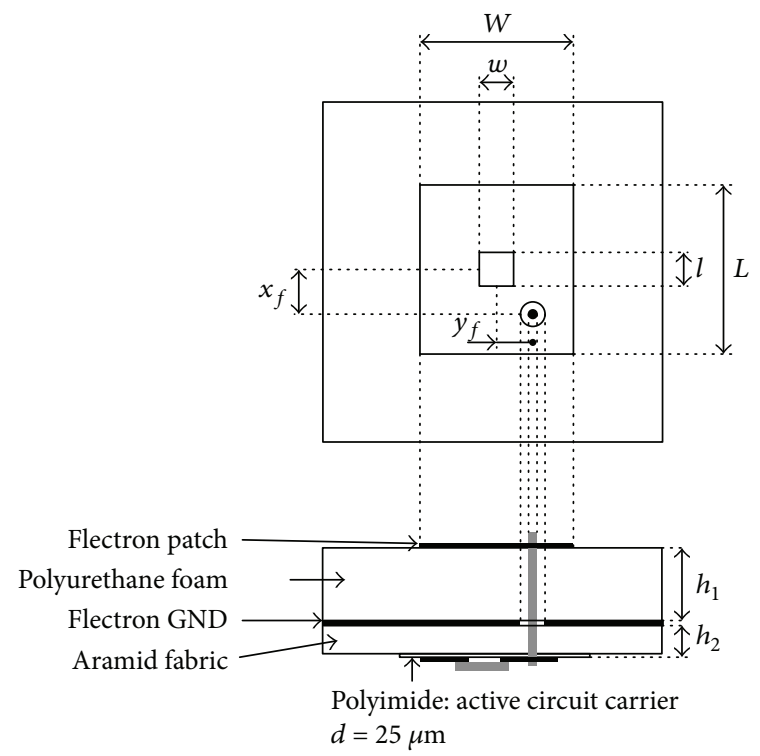

(a)

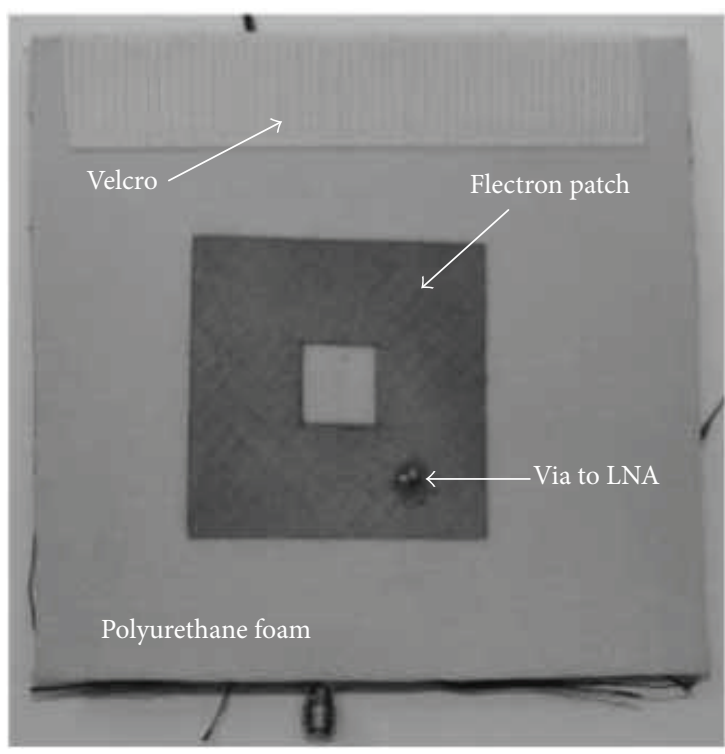

(b)

FIgURE 11: (a) Geometry of the active receiving wearable antenna. (b) Top view of the active receiving antenna [63].

stitches is longer than the exterior dimensions of the embroidered patch; thus, the resonant frequency of an embroidered antenna is lower than the copper equivalent due to the extended electrical length.

This paper also shown that fully textile embroidered $5 \mathrm{GHz}$ NMPA had $60 \%$ antenna efficiency with only $20 \%$ of the conductor coverage which is a highly satisfying outcome in terms of cost, flexibility, and antenna performance. Therefore, it will benefit potential wearable antenna applications since the cost of manufacturing and materials can be reduced.

3.2. Active Wearable Antennas. The first active wearable textile antenna was designed in 2010. This was an active receiving textile antenna in $2.45 \mathrm{GHz}$ ISM band and was addressed for the use in personal area networks [63]. The antenna was designed by integrating a low-noise amplifier on hybrid textile substrate and connecting it directly underneath a wearable patch antenna, as shown in Figure 11 [63]. Furthermore, the antenna gain was reported to be $5 \mathrm{dBi}$ and a noise figure of about $1.3 \mathrm{~dB}$.

After the fabrication of the first active textile antenna, the research moved towards application sector. A high degree of robustness, reliability, and autonomy is required for a wireless and wearable monitoring system without adding too much weight. In 2013 [64], active textile antenna was designed and fabricated for three different applications such as sensing, localization, and communication applications. 
After the fabrication of the full textile antenna, the fabricated area was further reused by placing active electronic elements underneath the antenna patch. Finally, the fabrication process was ended by adding an energy harvester directly on top of the antenna patch.

An active wearable antenna was also reported in [65] for the global positioning system (GPS) and satellite phone application. This article discussed about the design procedure of a combined GPS and iridium active antenna. During the construction of the square patch antenna, a flexible foam and fabric substrates were used. Then, the conductors were etched on thin copper-on-polyimide films. Later, a compact low-noise amplifier chip was integrated underneath the feed substrate. Finally, after simulation, they reported that the active antenna exhibited a gain higher than $25 \mathrm{dBi}$ and a $3 \mathrm{~dB}$ axial ratio bandwidth exceeding $183 \mathrm{MHz}$ in free-space conditions.

A novel autonomous wearable coordinated wireless sensor node network was developed in [66], where each flexible textile node was used for synchronous measurements and transmitting the data to a base station. On-body node-tonode communication was exploited for synchronize measurements. Finally, multiple autonomous nodes were used to share sensor data between these nodes. The extensive application area of this flexible node system includes the various rescue missions of workers and law enforcement officers, as well as the military and civilians.

3.3. Fabrication Challenges. The fabrication of the embroidered wearable antenna is a challenging process. The tension of the threads causes warping of the substrate and the antenna. Also, when a wearable textile antenna is worn on the human body, long term electromagnetic radiation poses potential health risks. Minimization of specific absorption rate is therefore a challenge for wearable patch antennas.

Additionally, patch antenna is usually low profile and easy to fabricate; thus, patch antenna is a good candidate as wearable antenna. The use of textile materials as substrates reduces surface wave losses and enhances the overall bandwidth.

3.4. Effect of Relative Humidity on Wearable Antennas. The influence of environmental relative humidity on textile antennas is investigated in [67]. All antenna prototypes were conditioned in a climatic test cabinet under the range of relative humidity from $10 \%$ to $90 \%$. For each relative humidity, the return loss characteristic was measured. Figure 12 displays the shifting and broadening of the return loss characteristic for a cotton-based antenna which is designed to operate at $2.45 \mathrm{GHz}$.

From the figure above, it can be concluded that the influence of relative humidity depends on both electromagnetic properties of the substrate material and relative permittivity. Also, the loss tangent increases with increasing relative humidity of the environment in which the antennas operate. This is a result of a change in electrical permittivity and loss tangent of the substrate material, influenced by the presence of moist.

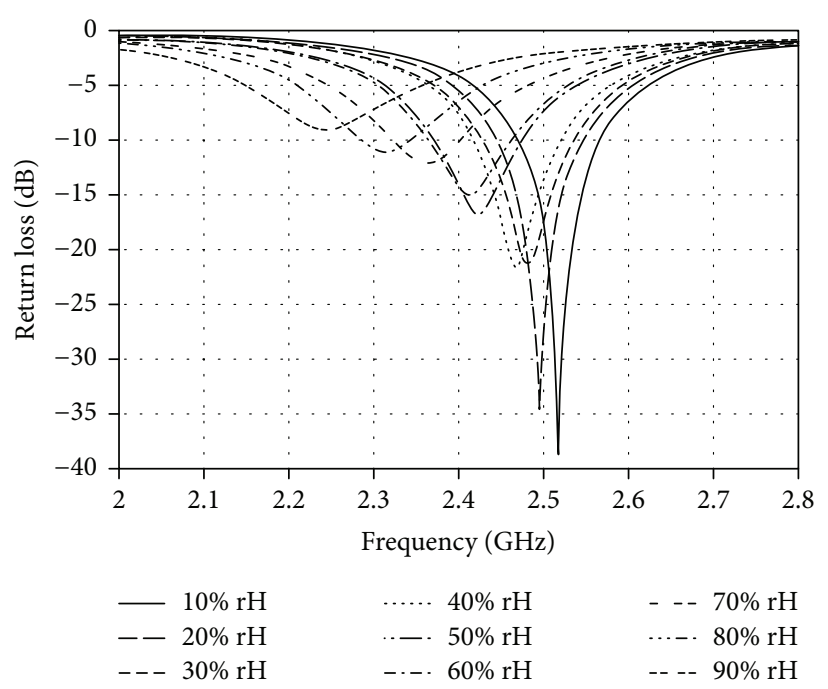

FIGURE 12: The effect of relative humidity on return loss [67].

3.5. Impact of Recurrent Washing on Wearable Antennas. In [68], Björninen et al. reported the impact of recurrent washing on wearable antennas. They studied the impact of recurrent washing on the performance of UHF RFID tags based on an electrotextile antenna. It is reported that prior washing the fully functional electrotextile tags showed a high attainable read range of $5.5 \mathrm{~m}$, then after washing the tags 7 times in a household washing machine in a $40^{\circ} \mathrm{C}$ program cycle with detergent reduced the read range to $2.8 \mathrm{~m}$. Thereafter, up to 10 wash repetitions, the performance remained constant.

So, it can be concluded that the recurrent washing of wearable antenna has a negative impact on the performance of the antenna.

In summary, the textile antenna is a promising approach for wearable applications. However, it is limited by choices of suitable fabric and resolution of the antenna geometry. Back radiation, humidity, and washing could be big challenges for practical applications. It is also limited to passive antennas, since active components with micrometer feature size could not be woven into fabrics.

\section{Substrate-Integrated Waveguide Antennas}

Since substrate-integrated waveguide antenna on paper, plastic, and textile is an emerging and promising research area, this session is dedicated to this topic. This topic covers paper-based substrate-integrated waveguide (SIW) components, plastic SIW components and antennas, and wearable textile SIW antennas.

4.1. Paper-Based SIW Components. The implementation of SIW structures on paper substrate using inkjet printing was first presented in [69]. Figure 13 shows the SIW interconnects and components that have been fabricated and tested on a multilayer low-cost and eco-friendly paper substrate [69]. 


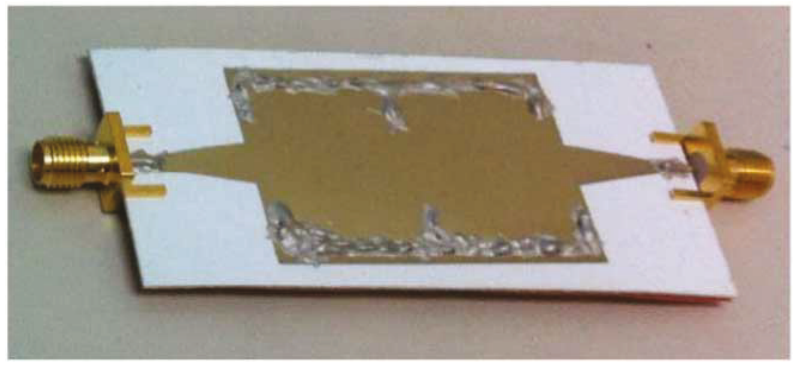

FIgURE 13: Implementation of a paper-based SIW filter [69].

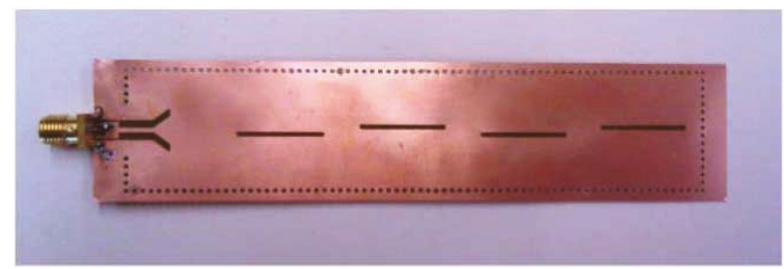

FIGURE 14: Implementation of SIW antenna on plastic substrate [70].

The operating frequency for the paper-based SIW filter was reported from 3 to $10 \mathrm{GHz}$. It is clearly seen that the achievable performance of paper-based SIW components is still menial to components based on commonly used dielectric material. But, this implementation of SIW structures on paper substrate represents the groundwork for future wireless systems and wearable devices.

4.2. Plastic SIW Components and Antennas. Electronic technologies are being converting from rigid to flexible due to low technology cost, available materials, and mechanically flexible substrates. Polyethylene terephthalate (PET) substrate has become an important candidate substrate material for the development of future flexible devices as well as conformal and wearable wireless antenna systems. Figure 14 shows the fabricated SIW antenna on plastic PET substrate. The operating frequency was reported at $5 \mathrm{GHz}$ frequency band [70].

Further performance of the plastic-based flexible antennas was verified after bending. Although the PET substrates have quite a high loss and the performance of the components cannot attain the results as of commonly used dielectric materials, the achieved results represent a fundamental step towards the implementation of cost-effective wireless terminals, which can be eventually integrated with other systems such as energy-harvesting systems, to obtain autonomous nodes for future wireless sensor networks.

4.3. Wearable Textile SIW Antennas. Figure 15 illustrates a novel wearable SIW antenna which was fabricated entirely from textile-based materials. The structure consists of a cavity-backed slot antenna which operates in the $2.45 \mathrm{GHz}$ industrial, scientific, and medical band, for short-range communication between rescue workers [71].

During the fabrication process, two conductive fabrics were glued on top of the textile substrate to assemble the

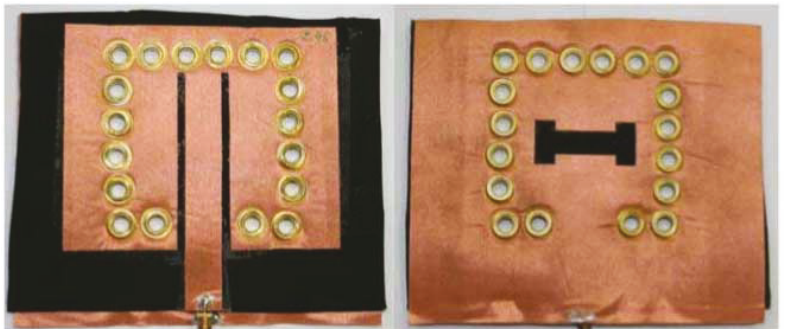

FIGURE 15: Cavity-backed SIW antenna on textile [71].

SIW textile antenna. The structure was then cut through to implement the via holes. Finally, the eyelets were fixed in the holes. The performance of the antenna was measured in terms of the input matching and radiation pattern. The prototype SIW antenna performance was reported to be comparatively good. Additionally, the measurements were also performed on the antenna after bending and integration into clothing which indicated the high-performance system to be suitable for on-body communication.

Finally, a compact and highly integrated wearable textile SIW antenna system was presented in [72]. This compact system was integrated on two flexible solar cells, a flexible power management system, and a microenergy cell. It is reported that the energy harvesting and power management hardware have negligible influence on the performance of the wearable textile antenna, which proves that the selected topology is suitable for a complex-integrated platform and the system could combine the energy scavenged from artificial light in an indoor environment.

In summary, SIW technology offers a simple and costeffective fabrication process for paper, plastic, and textile substrates. The structure allows easy integration of passive and active components onto the antenna, realizing complete systems on a textile carrier well suited for on-body use.

\section{Membrane-Based Phased-Array Antenna}

In addition to being costly, the conventional phased-array antenna technologies are not a suitable match for future space-based synthetic aperture radar (SAR) applications due to their large mass and stow volume (mass density of $8-15 \mathrm{~kg} / \mathrm{m}^{3}$ for antenna, electronics, and structure). As a result, supporting this huge payload antenna for existing launch vehicles is not practical. However, using flexible electronics and antennas could dramatically reduce the weight (mass density of $2 \mathrm{~kg} / \mathrm{m}^{3}$ ), stow volume, and associated cost of space-based SAR [73].

In [73], the architecture of the active membrane phased array is reported as in Figure 16. The active membrane phased array is composed of 2 layers, with radiating patches on one layer and their ground plane on the second layer. The membrane is reported as a $50 \mu \mathrm{m}$ thick Pyralux $^{\circledR}$ AP $^{\mathrm{TM}}$ (DuPont's copper-clad all-polyimide flexible circuit material) with $9 \mu \mathrm{m}$ copper layers. The T/R electronics are coupled to the patches via slot feeds. The antenna feed details are discussed in [74]. The T/R module, which is independently assembled and attached to the membrane 


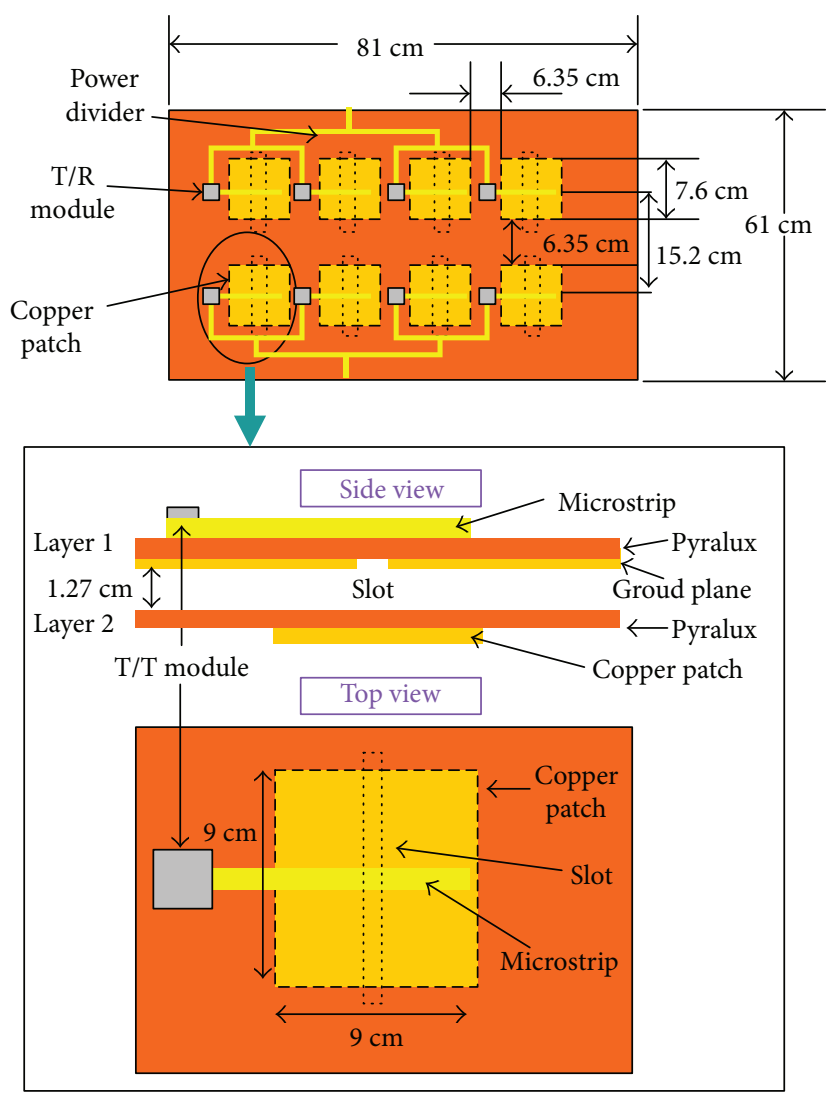

(a)

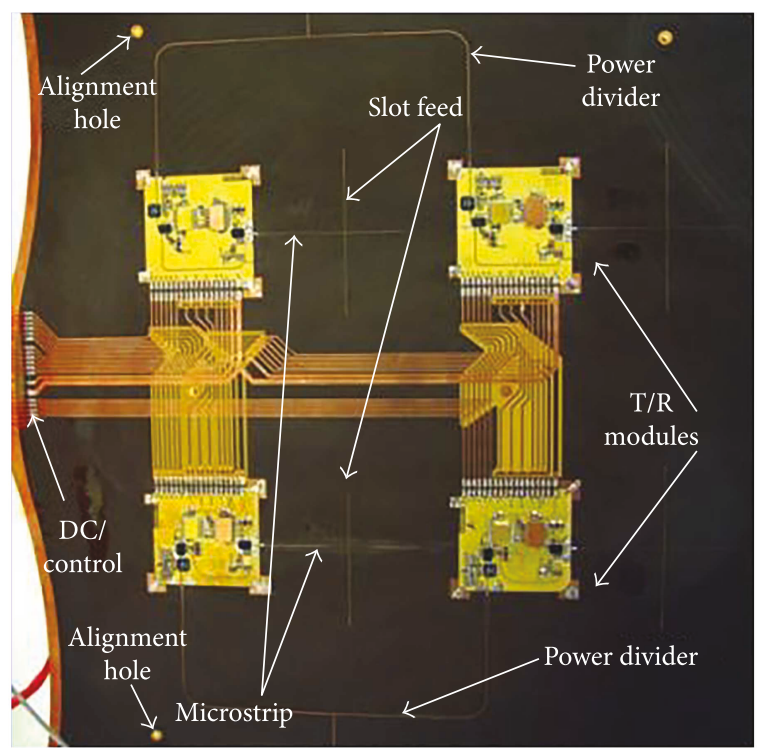

(b)

Figure 16: Membrane antenna architecture. (a) $2 \times 4$ element array. Unit cell top and side views. (b) A close-up of the membrane array showing four of the $\mathrm{T} / \mathrm{R}$ modules of the array [73].

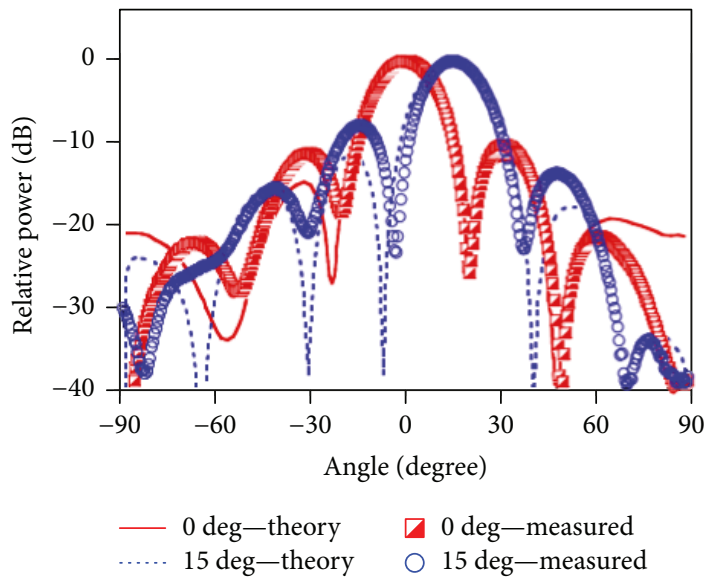

(a)

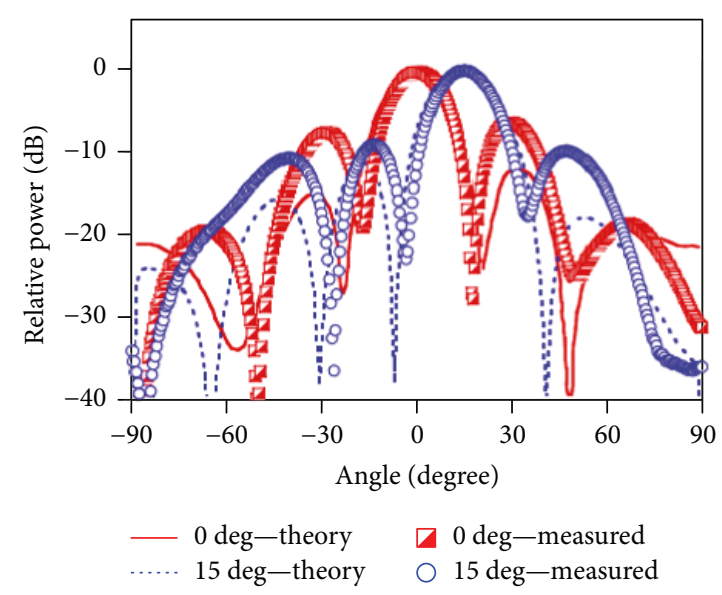

(b)

Figure 17: (a) Measured and theoretical receive antenna patterns for $0^{\circ}$ and $15^{\circ}$ steering angles. (b) Measured and theoretical transmit antenna patterns for $0^{\circ}$ and $15^{\circ}$ steering angles [73].

array, is a hybrid multilayer module on a flexible Pyralux AP substrate.

The measured and theoretical patterns for $0^{\circ}$ and $15^{\circ}$ steering angles in receive and transmit modes, respectively, are shown in Figure 17 [73]. The cross-polarization patterns are better than $-30 \mathrm{~dB}$ for all cases [73]. The main beam is steered to its expected scan angle for all cases.

The membrane antenna is based on copper-clad substrate, which is a subtraction process. In order words, antenna patterns and interconnect lines are produced 
using a traditional etching method. The achievable resolution of antenna geometry and interconnect lines limits the application of the technology to simple patterns and low RF frequencies. Furthermore, the subtraction process is not compatible with flexible $\mathrm{T} / \mathrm{R}$ modules to achieve true flexible active antennas.

\section{Conclusion}

In this review, we have identified and discussed the major fabrication techniques and associated materials used for the fabrication of flexible conformal antennas, including $3 \mathrm{D}$ printing technology, wearable textile technology, substrate-integrated waveguide technology, and membrane technology. The membrane antenna is based on copperclad substrate, which needs to be processed using a traditional etching method. The achievable resolution of antenna geometry and interconnect lines limits the application of the technology to simple patterns and low RF frequencies. The subtraction process is not compatible with true flexible active antennas. The textile antenna is a promising approach for wearable applications due to a comfort level. Active wearable textile antennas were developed incorporating a low-noise amplifier, solar cells, and so on. However, it is limited by choices of suitable fabric and resolution of the antenna geometry. Back radiation, humidity, and washing could be big challenges for practical applications. SIW technology offers a simple and costeffective fabrication process for paper, plastic, and textile substrates. The structure allows easy integration of passive and active components onto the antenna, realizing complete systems on a textile carrier well suited for on-body use. 3D aerosol and inkjet printing are promising technologies that could be used to fabricate accurate antenna geometries with resolution down to 5-10 microns and active components such as switches and amplifiers. 3D printing makes true flexible active antennas possible. It could even be used to directly print on fabrics for wearable antennas. Attaching 3D-printed flexible and elastic antennas onto fabrics could be another feasible approach for wearable antennas. However, printable nanomaterials are limited for the $3 \mathrm{D}$ printing process. The textile, SIW, and membrane antennas cost less to start with, since there is no need for the $3 \mathrm{D}$ printers. However, for large volume roll-to-roll fabrication, the cost of the above approaches is similar.

A lot of work has yet to be done to increase the performance of these antennas. To make progress in the development of various conformally flexible antennas, significant amounts of multidisciplinary collaborative efforts are expected, including material, manufacture, engineering, and integration. These efforts will eventually lead to numerous innovative, high-performance, low-cost, rapid deployable, and flexible antennas for various applications in the near future.

\section{Conflicts of Interest}

The authors declare that they have no conflicts of interest.

\section{Acknowledgments}

The authors would like to thank Jack Maceachern for his careful proofreading of this paper.

\section{References}

[1] J. Hu, "Overview of flexible electronics from ITRI's viewpoint," in 2010 28th VLSI Test Symposium (VTS), pp. 84-84, Santa Cruz, CA, USA, April 2010.

[2] A. Nathan and B. R. Chalamala, "Special issue on flexible electronics technology, part 1: systems and applications," Proceedings of the IEEE, vol. 93, no. 7, pp. 1235-1238, 2005.

[3] D. T. Pham, H. Subbaraman, M. Y. Chen, X. Xu, and R. T. Chen, "Light weight and conformal 2-bit, $1 \times 4$ phased-array antenna with CNT-TFT-based phase shifter on a flexible substrate," IEEE Transactions on Antennas and Propagation, vol. 59, no. 12, pp. 4553-4558, 2011.

[4] L. Zheng, M. B. Nejad, S. Rodriguez, L. Zhang, C. Chen, and H. Tenhunen, "System-on-flexible-substrates: electronics for future smart-intelligent world," in 2006 HDP'06 Conference on High Density Microsystem Design and Packaging and Component Failure Analysis, pp. 29-36, Shanghai, China, June 2006.

[5] R. J. Mailloux, Phased Array Antenna Handbook-Second Edition, Artech House, London, 2005.

[6] H. R. Khaleel, H. M. Al-Rizzo, and A. I. Abbosh, Design, Fabrication, and Testing of Flexible Antennas-Handbook, Intech Open Limited, London, 2013.

[7] A. Nathan, A. Ahnood, M. T. Cole et al., "Flexible electronics: the next ubiquitous platform," Proceedings of the IEEE, vol. 100, no. Special Centennial Issue, pp. 1486-1517, 2012.

[8] S. Zhang, "Design advances of embroidered fabric antennas," Loughborough University, 2014, https://dspace.lboro.ac.uk/ dspace-jspui/handle/2134/.

[9] M. Kubo, X. Li, C. Kim et al., "Stretchable microfluidic radiofrequency antennas," Advanced Materials, vol. 22, no. 25, pp. 2749-2752, 2010.

[10] D. E. Anagnostou, A. A. Gheethan, A. K. Amert, and K. W. Whites, "A direct-write printed antenna on paper-based organic substrate for flexible displays and WLAN applications," Journal of Display Technology, vol. 6, no. 11, pp. 558-564, 2010.

[11] 2016, http://www.antenna-theory.com, http://www.antennatheory.com/basics/efficiency.php.

[12] S. Zafri, Experimental Investigation of Dielectric Strength of Polymer Film, University of Windsor, Ontario, Canada, 2001, https://www.collectionscanada.gc.ca/obj/s4/f2/dsk3/ftp04/ MQ62224.pdf.

[13] "Selecting conductive materials for manufacturing inks (metallics, nanoparticles and graphene provide unique properties that are key to driving performance and growth)," 2015, http://www.printedelectronicsnow.com, Printed Electronics.

[14] 2018, http://www.novacentrix.com, https://www.novacentrix. com/products/metalon-inks/inkjet.

[15] S. B. Fuller, E. J. Wilhelm, and J. M. Jacobson, "Ink-jet printed nanoparticle microelectromechanical systems," Journal of Microelectromechanical Systems, vol. 11, no. 1, pp. 54-60, 2002.

[16] D. Wallace, D. Hayes, T. Chen et al., "Ink-jet as a MEMS manufacturing tool," in 2007 First International Conference on Integration and Commercialization of Micro and Nanosystems, pp. 1161-1168, Sanya, Hainan, China, January 2007. 
[17] C.-H. Tien, C.-H. Hung, and T.-H. Yu, "Microlens arrays by direct-writing inkjet print for LCD backlighting applications," Journal of Display Technology, vol. 5, no. 5, pp. 147-151, 2009.

[18] T. Sekitani, M. Takamiya, Y. Noguchi et al., "A large-area wireless power-transmission sheet using printed organic transistors and plastic MEMS switches," Nature Materials, vol. 6, no. 6, pp. 413-417, 2007.

[19] J. Lessing, A. C. Glavan, S. B. Walker, C. Keplinger, J. A. Lewis, and G. M. Whitesides, "Inkjet printing of conductive inks with high lateral resolution on omniphobic " $\mathrm{R}$ F paper" for paperbased electronics and MEMS," Advanced Materials, vol. 26, no. 27, pp. 4677-4682, 2014.

[20] A. A. Bessonov and M. N. Kirikova, "Flexible and printable sensors," Nanotechnologies in Russia, vol. 10, no. 3-4, pp. 165-180, 2015.

[21] R. J. Houben, Equipment for Printing of High Viscosity Liquids and Molten Metals, University of Twente, Enschede, Netherlands, 2012.

[22] B. K. Gale, M. A. Eddings, S. O. Sundberg, A. Hatch, J. Kim, and T. Ho, Comprehensive Microsystems - Low-Cost MEMS Technologies, Elsevier, London, 2008.

[23] J. Courbat, Y. Kim, D. Briand, and N. De Rooij, "Inkjet printing on paper for the realization of humidity and temperature sensors," in 2011 16th International Solid-State Sensors, Actuators and Microsystems Conference (TRANSDUCERS), pp. 1356-1359, Beijing, China, June 2011.

[24] T. Kawase, H. Sirringhaus, R. H. Friend, and T. Shimoda, "Inkjet printed via-hole interconnections and resistors for all-polymer transistor circuits," Advanced Materials, vol. 13, no. 21, pp. 1601-1605, 2001.

[25] S. H. Ko, J. Chung, N. Hotz, K. H. Nam, and C. P. Grigoropoulos, "Metal nanoparticle direct inkjet printing for lowtemperature 3D micro metal structure fabrication," Journal of Micromechanics and Microengineering, vol. 20, no. 12, article 125010, 2010.

[26] K. Black, J. Singh, D. Mehta, S. Sung, C. J. Sutcliffe, and P. R. Chalker, "Silver ink formulations for sinter-free printing of conductive films," Scientific Reports, vol. 6, no. 1, article 20814, 2016.

[27] S. F. Jahn, T. Blaudeck, R. R. Baumann et al., "Inkjet printing of conductive silver patterns by using the first aqueous particlefree MOD ink without additional stabilizing ligands," Chemistry of Materials, vol. 22, no. 10, pp. 3067-3071, 2010.

[28] O. Pabst, J. Perelaer, E. Beckert, U. S. Schubert, R. Eberhardt, and A. Tünnermann, "All inkjet-printed piezoelectric polymer actuators: characterization and applications for micropumps in lab-on-a-chip systems," Organic Electronics, vol. 14, no. 12, pp. 3423-3429, 2013.

[29] P. Calvert, "Inkjet printing for materials and devices," Chemistry of Materials, vol. 13, no. 10, pp. 3299-3305, 2001.

[30] Z. Zhang, X. Zhang, Z. Xin, M. Deng, Y. Wen, and Y. Song, "Synthesis of monodisperse silver nanoparticles for ink-jet printed flexible electronics," Nanotechnology, vol. 22, no. 42, article 425601, 2011.

[31] F. Zhang, C. Tuck, R. Hague et al., "Inkjet printing of polyimide insulators for the $3 \mathrm{D}$ printing of dielectric materials for microelectronic applications," Journal of Applied Polymer Science, vol. 133, no. 18, 2016.

[32] G.-K. Lau and M. Shrestha, "Ink-jet printing of micro-electromechanical systems (MEMS)," Micromachines, vol. 8, no. 6, p. 194, 2017.
[33] H. F. Schlaak, M. Jungmann, M. Matysek, and P. Lotz, "Novel multilayer electrostatic solid-state actuators with elastic dielectric," in Proceedings Volume 5759, Smart Structures and Materials 2005: Electroactive Polymer Actuators and Devices (EAPAD), pp. 121-133, San Diego, CA, USA, May 2005.

[34] D. T. K. Pham, "Carbon nanotube thin film transistor on flexible substrate and its applications as switches in a phase shifter for a flexible phased-array antenna," University of Texas, Austin, 2010, https://repositories.lib.utexas.edu.

[35] N. D. Sankır, Flexible Electronics: Materials and Device Fabrication, Virginia Polytechnic Institute and State University, 2005, https://theses.lib.vt.edu.

[36] H. P. Le, "Progress and trends in ink-jet printing technology," Journal of Imaging Science and Technology, vol. 42, no. 1, pp. 49-62, 1998.

[37] J. Brünahl, Physics of Piezoelectric Shear Mode Inkjet Actuators, Royal Institute of Technology, 2003, http://www.divaportal.org/smash/get/diva2:9351/FULLTEXT01.Pdf.

[38] W. Su, B. S. Cook, Y. Fang, and M. M. Tentzeris, "Fully inkjet-printed microfluidics: a solution to low-cost rapid three-dimensional microfluidics fabrication with numerous electrical and sensing applications," Scientific Reports, vol. 6, no. 1, 2016.

[39] H. Subbaraman, D. T. Pham, X. Xu et al., "Inkjet-printed twodimensional phased-array antenna on a flexible substrate," IEEE Antennas and Wireless Propagation Letters, vol. 12, pp. 170-173, 2013.

[40] M. Hedges and A. B. Marin, “3D aerosol jet ${ }^{\circledR}$ printing-adding electronics functionality to RP/RM," in DDMC 2012 Conference, pp. 1-5, Berlin, 2012.

[41] S. Agarwala, G. L. Goh, and W. Y. Yeong, "Optimizing aerosol jet printing process of silver ink for printed electronics," IOP Conference Series: Materials Science and Engineering, vol. 191, article 012027, 2017.

[42] R. Eckstein, "Aerosol jet printed electronic devices and systems," 2017, https://www.optomec.com/printed-electronics/ aerosol-jet-technology/.

[43] "Direct printing of 3D antenna and sensors for mobile device applications and the internet of things," 2017, https://www. optomec.com/printed-electronics/aerosol-jet-core-applications/internet-of-things/, http://www.Optomec.com.

[44] T. Blumenthal, V. Fratello, G. Nino, and K. Ritala, Aerosol Jet ${ }$ Printing onto $3 D$ and Flexible Substrates, Quest Integrated Inc., Kent, WA, USA, 2017.

[45] I. G. Elinoff, "Introducing a screen printed, flexible antenna for RFID devices," 2017, https://www.electronicproducts. com/Semiconductors/Applications/Introducing_a_screen_ printed_flexible_antenna_for_RFID_devices.aspx.

[46] R. Valmiro, H. Kitaguti, and S. E. Barbin, "A silk-screen printed RFID tag antenna," in 2015 Asia-Pacific Microwave Conference (APMC), Nanjing, China, December 2015.

[47] A. Moschos, T. Syrovy, L. Syrova, and G. Kaltsas, "A screenprinted flexible flow sensor," Measurement Science and Technology, vol. 28, no. 5, article 055105, 2017.

[48] PCI, "Dynamic surface tension and surface energy in ink formulations and substrates," 2001, https://www.pcimag.com/ articles/85879-dynamic-surface-tension-and-surface-energyin-ink-formulations-and-substrates, http://www.pcimag.com.

[49] B. Gupta, S. Sankaralingam, and S. Dhar, "Development of wearable and implantable antennas in the last decade: a 
review," in 2010 10th Mediterranean Microwave Symposium, pp. 251-267, Guzelyurt, Cyprus, August 2010.

[50] P. Salonen, Y. Rahmat-Samii, M. Schaffrath, and M. Kivikoski, "Effect of textile materials on wearable antenna performance: a case study of GPS antennas," in 2004 IEEE Antennas and Propagation Society International Symposium, vol. 1, pp. 459-462, Monterey, CA, USA, June 2004.

[51] R. Salvado, C. Loss, R. Gonçalves, and P. Pinho, "Textile materials for the design of wearable antennas: a survey," Sensors, vol. 12, no. 11, pp. 15841-15857, 2012.

[52] P. Salonen, L. Sydanheimo, and M. Keskilammi, "A small planar inverted-F antenna for wearable applications," in 1999. Digest of Papers. The Third International Symposium on Wearable Computers, San Francisco, CA, USA, October 1999.

[53] M. Tanaka and J. Jang, "Wearable microstrip antenna," IEEE Antennas and Propagation Society International Symposium, vol. 2, pp. 704-707, 2003.

[54] J. G. Santas, A. Alomainy, and Y. Hao, "Textile antennas for on-body communications: techniques and properties," in The Second European Conference on Antennas and Propagation, EuCAP 2007, pp. 1-4, Edinburgh, UK, 2007.

[55] C. Hertleer, L. Van Langenhove, H. Rogier, and L. Vallozzi, "A textile antenna for fire fighter garments," 2015, https://www. researchgate.net/publication/268414746.

[56] H. Abufanas, R. J. Hadi, C. Sandhagen, and A. Bangert, "New approach for design and verification of a wideband Archimedean spiral antenna for radiometric measurement in biomedical applications," in 2015 German Microwave Conference (GeMiC), pp. 127-130, Nuremberg, Germany, March 2015.

[57] A. Kiourti, J. Zhong, and J. L. Volakis, "Conformal spiral antenna based on conductive textile threads for load bearing applications," in International Workshop on Antenna Technology: Small Antennas, Innovative Structures and Application, pp. 1-21, Orlando, FL, USA, 2016.

[58] B. Ivšić, A. Galoić, and D. Bonefačić, "Embroidered textile logarithmic spiral antenna and its energy efficiency," in 2015 57th International Symposium ELMAR (ELMAR), pp. 157-160, Zadar, Croatia, September 2015.

[59] Z. Wang, L. Z. Lee, and J. L. Volakis, "A 10:1 bandwidth textile-based conformal spiral antenna with integrated planar balun," in 2013 IEEE Antennas and Propagation Society International Symposium (APSURSI), pp. 220-221, Orlando, FL, USA, July 2013.

[60] S. Zhang, A. Paraskevopoulos, C. Luxey, J. Pinto, and W. Whittow, "Broad-band embroidered spiral antenna for off-body communications," IET Microwaves, Antennas \& Propagation, vol. 10, no. 13, pp. 1395-1401, 2016.

[61] Y. P. Huang, "Effect of sewing types on flexible embroidery antennas in UHF band," in 2013 European Microwave Conference (EuMC), pp. 88-91, Nuremberg, Germany, October 2013.

[62] S. Zhang, W. Whittow, R. Seager, A. Chauraya, and J.(. Y.). C. Vardaxoglou, "Non-uniform mesh for embroidered microstrip antennas," IET Microwaves, Antennas \& Propagation, vol. 11, no. 8, pp. 1086-1091, 2017.

[63] F. Declercq and H. Rogier, "Active integrated wearable textile antenna with optimized noise characteristics," IEEE Transactions on Antennas and Propagation, vol. 58, no. 9, pp. 30503054, 2010.

[64] H. Rogier, S. Agneessens, A. Dierck et al., "Active textile antennas in professional garments for sensing, localisation and communication," in 2013 European, Microwave Conference (EuMC), pp. 850-853, Nuremberg, Germany, 2013.

[65] A. Dierck, H. Rogier, and F. Declercq, "A wearable active antenna for global positioning system and satellite phone," IEEE Transactions on Antennas and Propagation, vol. 61, no. 2, pp. 532-538, 2013.

[66] P. Vanveerdeghem, P. van Torre, C. Stevens, J. Knockaert, and H. Rogier, "Synchronous wearable wireless body sensor network composed of autonomous textile nodes," Sensors, vol. 14, no. 10, pp. 18583-18610, 2014.

[67] C. Hertleer, A. van Laere, H. Rogier, and L. van Langenhove, "Influence of relative humidity on textile antenna performance," Textile Research Journal, vol. 80, no. 2, pp. 177-183, 2009.

[68] T. Björninen, J. Virkki, L. Sydänheimo, and L. Ukkonen, "Impact of recurrent washing on the performance of electro-textile UHF RFID tags," in 2014 IEEE RFID Technology and Applications Conference (RFID-TA), pp. 251-255, Tampere, Finland, September 2014.

[69] R. Moro, M. Bozzi, S. Kim, and M. Tentzeris, "Novel inkjet-printed substrate integrated waveguide (SIW) structures on low-cost materials for wearable applications," in 2012 42nd European Microwave Conference (EuMC), pp. 72 75, Amsterdam, Netherlands, November 2012.

[70] R. Moro, A. Collado, S. Via, A. Georgiadis, and M. Bozzi, "Plastic-based substrate integrated waveguide (SIW) components and antennas," in 2012 42nd European Microwave Conference (EuMC), pp. 1007-1010, Amsterdam, Netherlands, November 2012.

[71] R. Moro, S. Agneessens, H. Rogier, and M. Bozzi, "Wearable textile antenna in substrate integrated waveguide technology," Electronics Letters, vol. 48, no. 16, pp. 985-987, 2012.

[72] S. Lemey and H. Rogier, "Substrate integrated waveguide textile antennas as energy harvesting platforms," in 2015 International Workshop on Antenna Technology (iWAT), pp. 23-26, Seoul, South Korea, March 2015.

[73] A. Moussessian, L. Del Castillo, J. Huang et al., "An active membrane phased array radar," in 2005 IEEE MTT-S International Microwave Symposium Digest, p. 4, Long Beach, CA, USA, June 2005.

[74] J. Huang and A. Moussessian, "Thin-membrane aperturecoupled L-band patch antenna," in 2004. IEEE Antennas and Propagation Society International Symposium, pp. 23882391, Monterey, CA, USA, June 2004. 


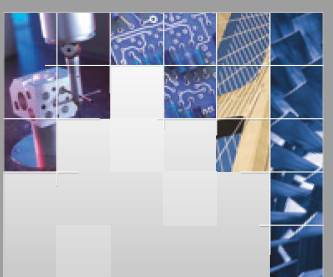

\section{Enfincering}
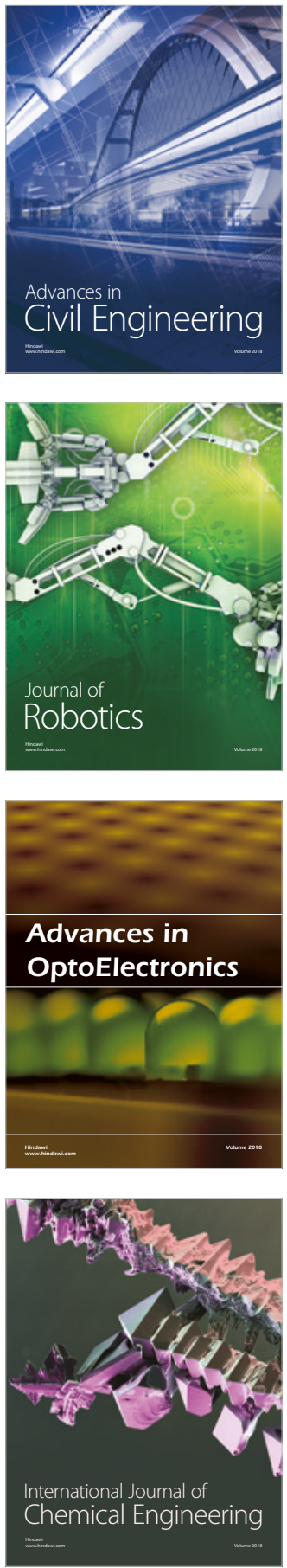

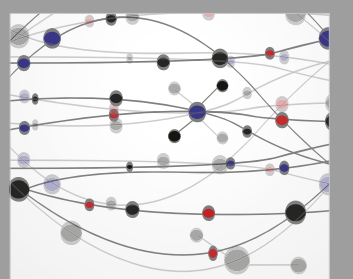

\section{Rotating \\ Machinery}

The Scientific World Journal

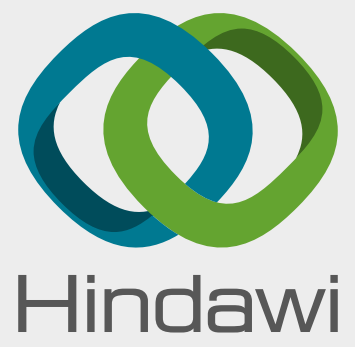

Submit your manuscripts at

www.hindawi.com
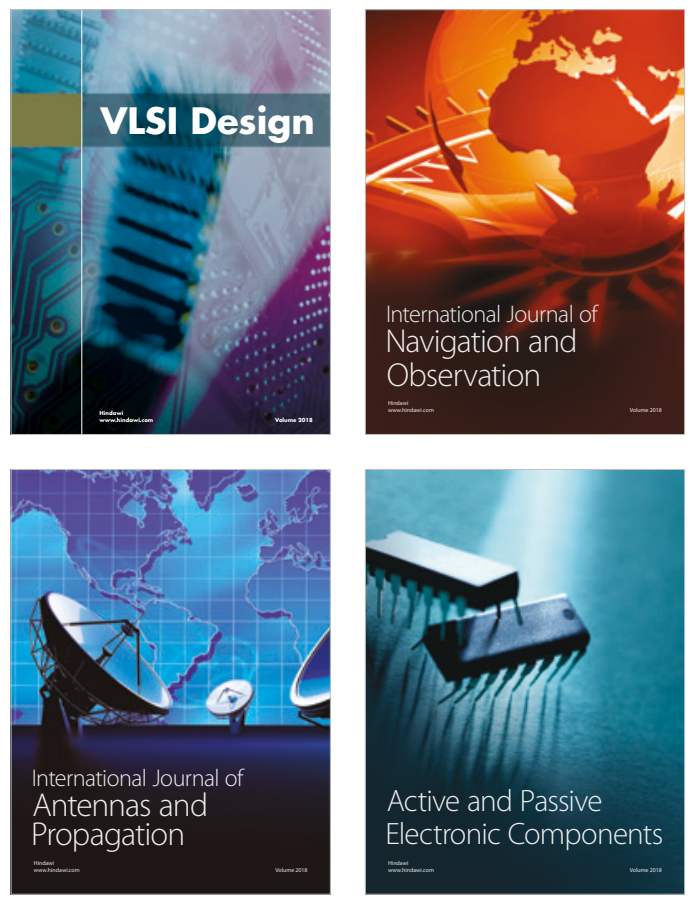
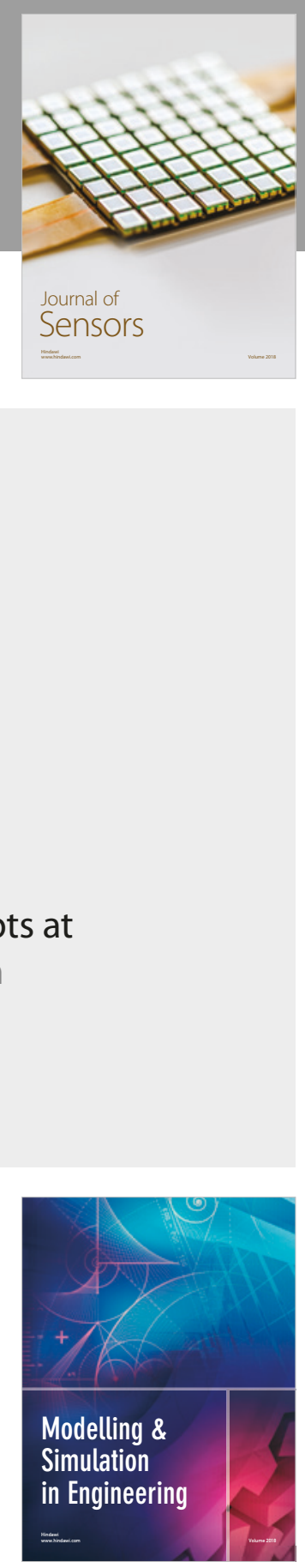

\section{Advances \\ Multimedia}
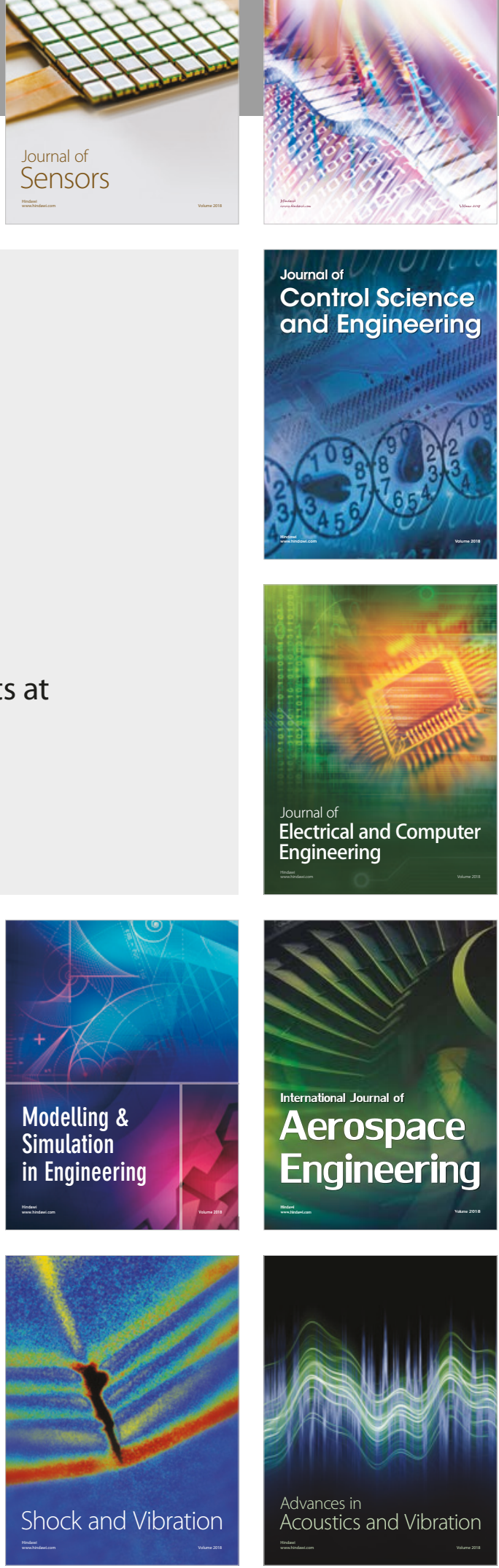